\title{
Recomendaciones de vacunación en pacientes con enfermedad inflamatoria intestinal (EII)
}

\author{
Recomendations of vaccination in patients with inflammatory \\ bowel disease (IBD)
}

\author{
C. Rodríguez ${ }^{1}$, O. Nantes ${ }^{1}$, M. Gómez ${ }^{1}$, M. Basterra ${ }^{1}$, J.L. Cabriada ${ }^{2}$, A. Arín ${ }^{1}$
}

\section{RESUMEN}

El concepto de enfermedad inflamatoria intestinal (EII) engloba tres entidades: la colitis ulcerosa (CU), la enfermedad de Crohn (EC) y la colitis inclasificable (CI). Estas enfermedades tienen en común el curso crónico y recidivante, alternando épocas de marcada actividad inflamatoria con otras quiescentes, en las que el paciente permanece asintomático.

Durante muchos años la base del tratamiento, sobre todo en las fases agudas, se basó en el uso de corticoides. Sin embargo, a lo largo de las últimas décadas hemos asistido a avances importantes desde el punto de vista terapéutico. Así se estima que, a lo largo de la evolución de la enfermedad, el $80 \%$ de los pacientes van a precisar corticoides, el $40 \%$ inmunomoduladores (IMM) y hasta un 20\% necesitará un fármaco biológico para el control de su enfermedad. Si bien todo ello se acompaña de una mejora en la calidad de vida, disminuyendo la necesidad de ingresos e intervenciones quirúrgicas, su uso implica también un incremento en el riesgo de sufrir infecciones, bien por gérmenes habituales en la comunidad o por gérmenes oportunistas.

Las infecciones, además, son causa de morbimortalidad asociada a EII y algunas de ellas son prevenibles con vacunas, de ahí la importancia que los programas de vacunación están adquiriendo en este grupo de pacientes.

Presentamos una revisión de la literatura al respecto y proponemos unas recomendaciones de vacunación para los pacientes diagnosticados de EII.

Palabras clave. Enfermedad inflamatoria intestinal. Vacunas. Inmunosupresión.

\begin{abstract}
The concept of inflammatory bowel disease (IBD) covers three entities: ulcerative colitis (UC), Crohn's disease (CD) and indeterminate colitis (IC). These diseases have in common a chronic and relapsing course, alternating periods marked by inflammatory activity with other quiescent periods, in which the patient is asymptomatic.

For many years treatment of the disease, especially in acute phases, was based on the use of corticoids. However, in recent decades we have witnessed significant advances from the therapeutic point of view. It is estimated that during the course of the disease's evolution $80 \%$ of patients will need corticoids, $40 \%$ immunomodulators (IMM), and as many as $20 \%$ will require a biological medicine to control their disease. While all of this is accompanied by an improvement in quality of life, less hospital admissions or surgical interventions, their use also involves an increase in the risk of suffering infections, either due to germs normally found in the community or opportunistic infections.

Moreover, infections are a cause of morbidity and mortality associated with IBD and some of them can be prevented with vaccinations, hence the importance that vaccination programs are acquiring in this groups of patients.

We present a review of the relevant literature and propose a vaccination protocol for patients diagnosed with IBD.
\end{abstract}

Key words. Inflammatory bowel disease. Vaccines. Immunosuppression.
1. Complejo Hospitalario de Navarra. Servicio de Aparato Digestivo

2. Hospital de Galdácano (coordinador grupo EIISVNPD)

\section{Correspondencia:}

Cristina Rodríguez Gutiérrez

Servicio de Digestivo-Unidad EII

Complejo Hospitalario de Navarra

C/ Irunlarrea, 3

31008 Pamplona

E-mail: crodrigg@cfnavarra.es

Este documento está respaldado por el grupo de EII de la Sociedad Vasco-Navarra de Patología Digestiva (SVNPD), actualmente en proceso de constitución. 


\section{INTRODUCCIÓN}

Pese a que la base fisiopatológica de la EII parece residir en una alteración de la inmunidad innata a nivel de la mucosa intestinal, en ausencia de otros procesos coexistentes, los pacientes con EII son inmunocompetentes ${ }^{1}$. Sin embargo, esta situación puede cambiar, de tal forma que a lo largo de la evolución de la enfermedad un porcentaje importante de pacientes se encontrarán en situación de inmunocompromiso incrementándose el riesgo de padecer una infección, bien por gérmenes habituales en la comunidad o por gérmenes oportunistas.

Las infecciones son causa de morbimortalidad asociada a la EII y algunas de ellas son prevenibles con vacunas. Por ello y aunque aún no existen guías internacionales aceptadas con pautas vacunales específicas al respecto, cada vez es más la información disponible acerca de su importancia.

El presente trabajo tiene por objetivo establecer unas recomendaciones de vacunación específica para pacientes diagnosticados de EII en las comunidades del País Vasco y Navarra y que han sido consensuadas por los miembros del grupo de EII de la Sociedad Vasco-Navarra de Patología Digestiva, actualmente en proceso de constitución.

\section{FUENTES}

Para la elaboración del presente documento se han revisado distintas fuentes:

- Recomendaciones del Ministerio de Sanidad y Consumo (MSC) de España referentes a vacunación en adul$\operatorname{tos}^{2-3}$.

- Recomendaciones de la Sociedad Española de Medicina Preventiva, Salud Pública e Higiene (SEMPSPH) ${ }^{4-5}$.

- Consenso de la ECCO (European Crohn's and Colitis Organisation), referente a prevención de infecciones oportunistas en pacientes con EII ${ }^{1}$.

- Recomendaciones para la vacunación en adultos del Advisory Committee on Inmunization Practices (EEUU) ${ }^{6}$.
- Recomendaciones del grupo joven de GETECCU (Grupo Español de Trabajo en Enfermedad de Crohn y Colitis ulcerosa) ${ }^{7}$.

- Bibliografía publicada al respecto.

\section{ESTADO DE INMUNOCOMPETENCIA}

Las recomendaciones en cuanto a pautas de vacunación varían en función de la inmunocompetencia del paciente.

Se considera inmunosuprimido a aquel paciente que, teniendo una EII, cumple algunos de los siguientes supuestos:

1. Tratamiento con fármacos inmunosupresores (IS)

2. Malnutrición

3. Coexistencia de inmunosupresión (VIH positivo, hipoesplenia, esplenectomía...).

La relación de fármacos que convierten a un paciente con EII en inmunosuprimido aparece reflejada en la tabla 1. Aunque no se ha podido establecer un riesgo específico para cada fármaco, sí sabemos que éste aumenta de forma significativa con la asociación de varios IS $^{8-9}$.

Tabla 1. Fármacos inmunosupresores

Prednisona $\geq 20 \mathrm{mg} /$ día (o equivalente) du-
rante $\geq 2$ semanas
Tiopurinas (azatioprina, mercaptopurina)
Metotrexato
Calcineurínicos (ciclosporina, tacrolimus)
Biológicos (infliximab, adalimumab y otros)

La malnutrición se considera, en general, una de las principales causas de disfunción inmune y en el caso de la EII suele aparecer asociada a formas clínicas más graves. Se considera que un paciente está en riesgo nutricional cuando el consumo y/o la absorción de nutrientes son deficientes. A ello pueden contribuir además de la actividad de la enfermedad otros factores como la anorexia secundaria al incremento de citoquinas, la dispepsia asociada a la azatioprina o el metronidazol, el sobrecrecimiento bacteriano en pacientes con estenosis intestinal, la malabsorción de calcio 
mediada por corticoides, la afectación o resección ileal, la sintomatología suboclusiva o el intestino corto.

La forma más sencilla de aproximarnos al estado nutricional de un paciente es mediante el cálculo del índice de masa corporal (IMC) que consiste en dividir el peso, expresado en $\mathrm{kg}$, entre la talla expresada en $\mathrm{m}^{2}\left(\mathrm{~kg} / \mathrm{m}^{2}\right)$. En pacientes con sobrepeso este índice puede infraestimar la situación real por lo que deberemos tener en cuenta otros parámetros bioquímicos como la albúmina $(<3,5 \mathrm{gr} / \mathrm{dL})$ o la transferrina $(<200$ $\mathrm{mg} / \mathrm{dL}$ ) ambos en relación con la malnutrición proteica. Pacientes con pérdida ponderal $>10 \%$ de su peso basal en los 6 meses previos, es probable que también estén en riesgo nutricional.

Por tanto en todas estas situaciones y en aquellos casos con $\mathrm{IMC}<20 \mathrm{~kg} / \mathrm{m}^{2}$ deberíamos solicitar la colaboración de un equipo de nutricionistas.

Los pacientes encuadrables en alguno de los 3 grupos anteriores -pacientes con inmunocompromiso- tienen mayor riesgo de contraer una infección, bien por gérmenes habituales en la comunidad o por gérmenes oportunistas.

No debemos olvidar que el principal factor de riesgo para contraer una infección oportunista es el uso de 2 o más fármacos inmunosupresores, sobre todo si el paciente tiene más de 50 años. Además, en el caso de la EC la afectación colónica, en comparación con la ileal aislada, también constituye un factor de riesgo mientras que en el caso de la CU este riesgo parece no guardar relación con la extensión de la enfermedad $^{8-9}$.

En el grupo de pacientes sin inmunocompromiso, es decir los que no cumplen los criterios previos, si bien el riesgo de infecciones es similar al de la población general, hay que tener en cuenta tres consideraciones especiales:

1. El estado de inmunocompetencia de un paciente puede modificarse a lo largo de la evolución de la enfermedad.

2. Hay vacunas que pueden estar contraindicadas en caso de cambiar la situación de inmunocompetencia

del paciente; por ejemplo, todas las elaboradas a partir de microorganismos vivos atenuados que están contraindicadas en pacientes inmunocomprometidos (Tabla 2).

Tabla 2. Vacunas de microorganismos vivos

Fiebre amarilla

Varicela

Tuberculosis

Triple vírica (sarampión, rubéola, parotiditis)

Polio oral

Influenza intranasal

Fiebre tifoidea oral

3. La respuesta inmune a las vacunas en pacientes inmunocomprometidos puede ser menor, no asegurando una correcta protección del paciente.

Por todo ello y dado que a lo largo de su evolución aproximadamente el $80 \%$ de los pacientes van a precisar corticoides, el $40 \%$ inmunomoduladores y el $20 \%$ fármacos biológicos, el mejor momento para iniciar el programa de vacunación es al diagnóstico de la enfermedad.

Los microorganismos a tener en cuenta se recogen en la tabla 3 .

Tabla 3 Microorganismos

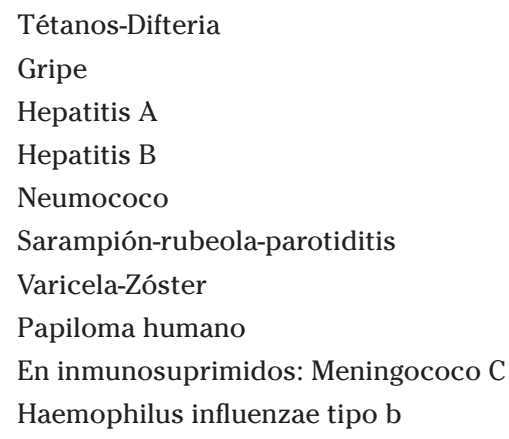

Fuente: grupo joven de GETECCU-2010

Pese a que las vacunas tienen un efecto inmunomodulador no existen estudios que demuestren que su administración pueda influir en el curso clínico de la enfermedad ${ }^{10}$. 


\section{TIPOS DE VACUNAS}

La vacunación (inmunización pasiva) tiene como objetivo inducir, en un sujeto sano, una respuesta inmune protectora específica. Las vacunas actualmente comercializadas se clasifican en víricas y bacterianas y, a su vez, cada una de ellas se dividen en vivas-atenuadas y muertasinactivadas.

Las vacunas atenuadas se consiguen mediante la selección de mutantes avirulentos o de virulencia atenuada que originan una infección inaparente o mínimamente sintomática e inducen una inmunidad semejante a la adquirida tras la infección natural. La respuesta inmunitaria suele ser intensa y de larga duración por lo que habitualmente se administra una sola dosis.

Las vacunas inactivadas pueden contener microorganismos enteros (o fragmentos de los mismos) inactivados por métodos físicos o químicos, o antígenos segregados (toxoides) como el HBsAg o los polisacáridos capsulares del neumococo, el meningococo o el Haemophilus influenzae. En estos casos la respuesta inmune suele ser menos intensa y duradera por lo que con frecuencia se requieren dosis de recuerdo.

\section{TIEMPOS DE ESPERA}

Para el caso de vacunas vivas-atenuadas no debemos olvidar que el control de la enfermedad siempre prima sobre la conveniencia de vacunar:

- Si decidimos vacunar primero deberemos esperar un mínimo de 14 días antes de iniciar el tratamiento con fármacos IS.

- Si el paciente lleva o ha llevado tratamiento IS o corticoideo se aconseja esperar 3 meses antes de iniciar la vacunación. La ECCO admite un intervalo de sólo 1 mes para los pacientes que sólo han recibido corticoides $^{1}$.

\section{ACTITUD EN CONSULTA}

Deberemos solicitar el calendario vacunal a todos los pacientes.

En los casos de hepatitis A, hepatitis B, sarampión, rubéola, parotiditis y varicela siempre que por calendario vacunal no sea posible asegurar una correcta inmunización se aconseja realizar serología previa de cara a determinar el estado de inmunización del paciente. En el caso de la hepatitis B, además, siempre habrá que confirmar la eficacia de la vacunación mediante titulación de Ac anti-HBs que se determinará entre 1-3 meses después de la administración de la última dosis.

En los casos restantes las vacunas se pueden administrar directamente.

\section{PAUTAS}

Las pautas de vacunación se resumen en la tabla 4.

\section{Difteria-tétanos}

\section{Corynebacterium diphtheriae - Clostridium tetani}

La difteria es una infección aguda de las vías respiratorias altas caracterizada por la aparición de membranas grisáceas sobre todo a nivel faringo-amigdalar, rodeadas de tejido inflamatorio. Puede ser paucisintomática o producir cuadros sistémicos con afectación de miocardio y sistema nervioso periférico. El último caso declarado en España data de 1986.

El tétanos es una enfermedad aguda producida por toxinas que se caracteriza por contracciones musculares dolorosas, inicialmente en maseteros y cara y después en cuello y tronco. La puerta de entrada son heridas que se contaminan por esporas que germinan en condiciones de anaerobiosis. Los casos declarados en España corresponden a personas no vacunadas o con vacunación incompleta ( $\leq 2$ dosis). Entre 1997-2006 la mortalidad media fue de 7 pacientes/año. 
Tabla 4. Pautas de vacunación

\begin{tabular}{|c|c|c|c|}
\hline Vacuna & Tipo & Previo & Pauta \\
\hline Difteria-Tétanos & toxoide (Td) & - & actualizar \\
\hline Gripe & v. inactivados & - & anual \\
\hline VHA & v. inactivados & $\begin{array}{l}\text { Serología } \\
\text { IgG }\end{array}$ & 2 dosis $(0-6 \mathrm{~m})$ \\
\hline VHB & $\begin{array}{c}\text { HBsAg } \\
\text { (recombinante) }\end{array}$ & $\begin{array}{l}\text { Serología } \\
\text { anti-HBs }\end{array}$ & $\begin{array}{c}3 \text { dosis }(0-1-6 \mathrm{~m}) \\
\text { Serología post }\end{array}$ \\
\hline Neumococo & polisacáridos & - & dosis única \\
\hline Triple vírica & v. vivos atenuados & $\begin{array}{l}\text { Serología } \\
\text { IgG }\end{array}$ & $\begin{array}{c}1-2 \text { dosis } \\
(\geq 28 \text { d intervalo) }\end{array}$ \\
\hline VVZ & v. vivos atenuados & $\begin{array}{l}\text { Serología } \\
\text { IgG }\end{array}$ & $\begin{array}{c}2 \text { dosis } \\
(0-1 \text { mes })\end{array}$ \\
\hline Papiloma humano & $\begin{array}{l}\text { proteínas } \\
\text { recombinantes }\end{array}$ & $\begin{array}{l}\text { † 11-14 años } \\
\text { (< } 26 \text { años })\end{array}$ & $\begin{array}{c}\text { divalente }(0-1-6 \mathrm{~m}) \\
\text { tetravalente }(0-2-6 \mathrm{~m}) \\
+ \\
\text { citologías }\end{array}$ \\
\hline Meningococo C & oligo/polisacáridos & - & 1 dosis \\
\hline Hib & polisacáridos & - & 1 dosis \\
\hline
\end{tabular}

En España, desde 1975, está indicada la vacunación universal.

La vacuna del tétanos y de la difteria son toxoides. Suelen presentarse en combinación con la vacuna de la tosferina que es acelular. Su administración es intramuscular (IM).

Tipos: monovalente tétanos, combinada tétanos-difteria (Td) y combinada tétanos-difteria-tosferina: DTPa (inmunización primaria en población pediátrica) y dTPa (vacuna de recuerdo aprobada en adolescentes y edad adulta).

Todos los pacientes diagnosticados de EII, con independencia de su estado de inmunocompetencia, deberán actualizar o en su defecto iniciar la vacunación. Las pautas son las mismas que en la población general $^{3}$. Se asume que en pacientes inmunocomprometidos las tasas de respuesta pueden ser menores aunque no se han descrito esquemas específicos para estas situaciones.
Las pautas a seguir son:

- Adulto correctamente inmunizado en la infancia: en este caso se aconseja dosis de recuerdo (Td) a los 50-65 años. Recordamos que la vacunación en población infantil consta de 5 dosis (DTPa) a los 2, 4, 6 y 15-18 meses y a los 6 años, seguida de dosis de recuerdo (dTPa) a los 13-16 años.

- Vacunación incompleta: en estos casos nunca se reinicia la vacunación ya que cada dosis administrada previamente tiene su valor. Se aconseja dosis de recuerdo cada 10 años hasta un total de 5 dosis (incluidas todas).

- Primovacunación en adultos: se aconseja en aquellos pacientes en los que no sea posible asegurar la vacunación previa. Se administran 3 dosis (Td) según esquema 0/1-2/6-12 meses. Posteriormente se administrará una dosis de recuerdo cada 10 años hasta completar un total de 5 dosis (incluidas las 3 de la primovacunación). 


\section{Gripe}

\section{Influenza virus}

Se denomina así al cuadro clínico agudo producido tras la infección por los virus de la gripe. Es una enfermedad de gran trascendencia desde el punto de vista de la salud pública por la elevada capacidad de difusión viral y con importante morbimortalidad asociada. Aunque existe una gran variabilidad clínica, los 4 síntomas típicos son fiebre, cefalea, afectación del estado general y sintomatología respiratoria. La complicación más frecuente es la neumonía (primaria y/o secundaria) seguida de la miositis-rabdomiolisis, afectación de SNC y pericarditis. Según datos del MSC, en España supone una media de 3000 defunciones anuales.

En la población sana está indicada en personas mayores de 65 años, ya que a partir de esa edad se incrementa el riesgo de hospitalizaciones y muerte por complicaciones de la enfermedad, y en personas que por motivos sociales, familiares o laborales puedan transmitir la enfermedad a personas de riesgo. Tienen más riesgo de complicaciones los pacientes con patología pulmonar, cardíaca, hepática, metabólica (incluida la diabetes) o renal crónica, hemoglobinopatías e inmunosuprimidos en general.

Vacuna trivalente inactivada. Administración IM (o subcutánea profunda) en región deltoidea.

En pacientes sin criterios de inmunosupresión se asumen las mismas indicaciones de la población general y se aconseja en personas > 65 años y grupos de riesgo profesional o familiar (personal sanitario, trabajadores de instituciones geriátricas, convivientes con pacientes pertenecientes a grupos de riesgo).

En pacientes con EII y criterios de inmunosupresión la vacunación debe ser anual. La respuesta a la vacuna en pacientes en tratamiento con tiopurinas o ciclosporina puede ser menor.

Cuando la vacuna esté indicada se administrará una dosis anual. Está contraindicada en alérgicos al huevo ya que éste es el medio de cultivo viral y también en alérgicos a los aminoglucósidos ya que la neomicina se utiliza en el proceso de elaboración de la vacuna ${ }^{2}$.

\section{Hepatitis A}

Virus de la hepatitis A (VHA)

El VHA es un enterovirus de transmisión fecal-oral que produce un cuadro de hepatitis aguda, en muchas ocasiones asintomática y en otras, ictérica. Su curso suele ser benigno, con resolución espontánea en la mayor parte de las ocasiones, si bien puede evolucionar a formas fulminantes que precisen transplante hepático. No está exenta de mortalidad que, aunque poco frecuente, aumenta con la edad de infección pudiendo alcanzar hasta el $1.8 \%$ en pacientes mayores de 49 años con fallo hepático fulminante ${ }^{11}$.

Su prevalencia es más alta en países poco desarrollados en los que la infección se produce en edades tempranas. En nuestro medio, a lo largo de las últimas décadas se ha producido un retraso en la edad de infección que va en paralelo a la mejora de las condiciones sociosanitarias. Así la prevalencia de seropositivos en los nacidos entre 1967-1971 alcanzaba el 41\% mientras que en la cohorte 1987-1990 no supera el $4 \%$ (datos del MSC).

La SEMPSPH, en septiembre de 2012, publicó un protocolo de vacunación específico para pacientes con EEII, en donde se aconsejó vacunación frente al VHA en todos los pacientes no inmunizados. De esta forma se pretende evitar la infección aguda en la edad adulta, momento en el que el cuadro clínico puede revestir mayor gravedad.

La vacuna son virus inactivados. Administración IM, en deltoides.

En EII y siguiendo las recomendaciones de la Sociedad Española de Medicina Preventiva aconsejaremos vacunación a todo paciente no inmunizado (serología IgG negativa), tanto a los inmunocompetentes como a los inmunosuprimidos.

La $\mathrm{ECCO}^{1}$ no la incluye entre las recomendaciones generales para pacientes con EII, limitando su prescripción a viajeros a áreas endémicas. 
La pauta es dos dosis separadas por un intervalo de 6-12 meses.

\section{Hepatitis B}

\section{Virus de la hepatitis $B(V H B)$}

$\mathrm{Al}$ igual que en el caso del VHA a todos los pacientes diagnosticados de EII se les debería realizar, en el mismo momento del diagnóstico, una serología VHB ${ }^{12}$. En España, según datos recientemente publicados ${ }^{13}$ menos del 1\% de los pacientes con EII son HBsAg positivo y menos del $10 \%$ son anti$\mathrm{HBc}$ positivo. El resto, salvo los que por edad o grupo de riesgo ya lo estén, tendrán indicación de vacunarse frente al VHB.

En población general se aconsejan 3 dosis de $20 \mu \mathrm{g}$ según pauta 0-1-6 meses, obteniéndose tasas de respuesta superiores al 95\%. Aunque los datos publicados al respecto son escasos, cada vez es mayor la evidencia de menor respuesta en los pacientes diagnosticados de EII, con tasas de respuesta en torno al $34 \%$ con un ciclo y del $60 \%$ después de dos ciclos de vacunación ${ }^{14-15}$. En un intento por mejorar estos resultados se ha sugerido la vacunación con dosis doble $(40 \mu \mathrm{g})$ en todos los pacientes diagnosticados de EII con independencia de su estado de inmunosupre- sión. Datos publicados recientemente demuestran que utilizando dosis más altas la tasa de respuesta puede elevarse hasta el $75 \%$ después de un único ciclo de vacunación ${ }^{16}$.

Los pacientes vacunados desarrollan Ac anti-HBs. Se aconseja medir niveles de anti-HBs entre 1-3 meses después de la administración de la última dosis. Aunque no hay unanimidad al respecto, en general, y siguiendo las directrices de la OMS, se asume que títulos de anti-HBs $\geq 10 \mathrm{UI} / \mathrm{L}$ son protectores $^{17}$.

Se han descrito pautas vacunales alternativas, habitualmente aplicadas a situaciones especiales (viajes a zonas endémicas...) en las que interesa una rápida inmunización o en pacientes en los que se sospecha una pobre adhesión al tratamiento: por ejemplo 0-1-2 meses o 0-7-21 días. En ellas, y dado que el intervalo entre dosis se reduce, los niveles absolutos de anti-HBs suelen ser menores por lo que se aconseja complementar con una dosis adicional a los 12 meses de la primera.

La vacuna frente al VHB es de tipo recombinante y de administración IM.

En base a la menor respuesta en pacientes con EII nosotros proponemos dividirlos en función de su estado de inmunocompetencia (Tabla 5 y Tabla 6).

Tabla 5. Vacuna VHB en inmunocompetentes

\begin{tabular}{|c|c|c|c|c|}
\hline Vacuna VHB & Anti-HBs & Pauta & Seguimiento Anti-HBs & Actitud \\
\hline \multirow{3}{*}{$20 \mu \mathrm{g}$} & $\geq 10 \mathrm{UI} / \mathrm{l}$ & - & - & - \\
\cline { 2 - 5 } $0-1-6 \mathrm{~m}$ & $<10 \mathrm{UI} / \mathrm{l}$ & $\begin{array}{c}\text { revacunar } \\
40 \mu \mathrm{g} \\
0-1-6 \mathrm{~m}\end{array}$ & $\geq 10 \mathrm{UI} / \mathrm{l}$ & - \\
\cline { 3 - 5 } & & $<10 \mathrm{UI} / \mathrm{l}$ & consejo \\
\hline
\end{tabular}

Tabla 6. Vacuna VHB en inmunosuprimidos

\begin{tabular}{|c|c|c|c|c|}
\hline Vacuna VHB & Anti-HBs & Pauta & Seguimiento Anti-HBs & Actitud \\
\hline \multirow{3}{*}{$\begin{array}{c}40 \mu \mathrm{g} \\
0-1-6 \mathrm{~m}\end{array}$} & $\geq 10 \mathrm{UI} / \mathrm{l}$ & - & - & Anti-HBs anual \\
\hline & \multirow{2}{*}{$<10 \mathrm{UI} / \mathrm{l}$} & \multirow{2}{*}{$\begin{array}{c}\text { revacunar } \\
40 \mu \mathrm{g} \\
0-1-6 \mathrm{~m}\end{array}$} & $\geq 10 \mathrm{UI} / \mathrm{l}$ & Anti-HBs anual \\
\hline & & & $<10 \mathrm{UI} / \mathrm{l}$ & consejo \\
\hline
\end{tabular}


a) EII sin inmunocompromiso

En este grupo de pacientes, en principio, podemos asumir las pautas vacunales de la población general. A todos los pacientes no inmunizados aconsejaremos vacunación con 3 dosis de $20 \mu \mathrm{g}$ según esquema 0-1-6 meses. Realizaremos titulación de anti-HBs entre 1-3 meses tras la administración de la última dosis. Si los títulos son $\geq 10 \mathrm{UI} / \mathrm{L}$ consideraremos al paciente correctamente inmunizado y no haremos nada más.

Aunque con el paso del tiempo los títulos de anti-HBs pueden disminuir e incluso desaparecer, en pacientes no inmunosuprimidos y con respuesta previa correcta a la vacunación no suele haber infecciones clínicamente relevantes (memoria inmunológica).

Si los títulos de anti-HBs son $<10 \mathrm{UI} / \mathrm{L}$, aconsejaremos un segundo ciclo completo de vacunación, aunque en este caso utilizaremos dosis doble $(40 \mu \mathrm{g})$ y el mismo esquema 0-1-6 meses. Si tras este segundo ciclo los niveles de anti-HBs son $\geq$ $10 \mathrm{UI} / \mathrm{L}$ no haremos nada más. Si siguen siendo $<10 \mathrm{UI} / \mathrm{L}$, informaremos al paciente acerca de formas de contagio del VHB y medidas preventivas posibles a tener en cuenta.

Tras fracaso de dos ciclos de vacunación, en ningún caso está indicado iniciar otro tercer ciclo.

En personas que precisen vacunarse del VHA y VHB cabe la posibilidad de hacerlo conjuntamente gracias a la vacuna TWINRIX® (HBsAg $20 \mu g$ + VHA Ag 720U). En estos casos el esquema que se sigue también es 0-1-6 meses (administración IM).

\section{b) EII con inmunocompromiso}

En éstos aconsejaremos dosis doble desde el inicio $(40 \mu \mathrm{g})$ manteniendo el esquema previo de 0-1-6 meses. Al igual que en el caso anterior realizaremos titulación de anti-HBs entre 1-3 meses tras la última dosis.

Si los títulos de anti-HBs son $\geq 10 \mathrm{UI} / \mathrm{L}$ consideraremos al paciente correctamente inmunizado. No está demasiado claro si estos pacientes necesitan algún seguimiento especial. Como se trata de pacien- tes inmunosuprimidos se podría aconsejar titulación anual de anti-HBs con administración de una dosis de recuerdo $(40 \mu \mathrm{g})$ en caso de descenso de los mismos a títulos $<10$ UI/L. Se cree que en este grupo de pacientes la memoria inmunológica puede no ser suficiente para evitar una infección clínicamente relevante ${ }^{12}$. Es una estrategia similar a la que se sigue en las unidades de hemodiálisis y que ha demostrado su utilidad en pacientes pediátricos con enfermedad de Crohn y tratamiento con infliximab $^{18}$.

Si tras las 3 dosis los títulos de antiHBs son < $10 \mathrm{UI} / \mathrm{L}$ aconsejaremos un ciclo completo de revacunación, de nuevo a dosis doble $(40 \mu \mathrm{g})$ y con el mismo esquema (0-1-6 meses). Tras esto la actitud será la misma descrita previamente: titulación de anti-HBs anual en aquellos que han alcanzado títulos y consejos educacionales si persistieran < $10 \mathrm{UI} / \mathrm{L}$.

En este grupo no cabe la posibilidad de vacunación conjunta con el VHA dado que la dosis de HBsAg contenida en TWINRIX® es de $20 \mu$ g.

\section{Neumococo}

\section{Streptococcus pneumoniae}

Con frecuencia es un colonizador de las vías respiratorias altas de sujetos sanos (5$60 \%)$. La infección aguda produce un amplio espectro clínico con formas leves (infecciones del tracto respiratorio superior, otitis, sinusitis...) o invasivas (neumonía, meningitis, endocarditis, bacteriemias...). En nuestro medio causa el 50\% de las neumonías comunitarias en adultos y el $40 \%$ de las meningitis bacterianas en adultos. La mortalidad se asocia a formas invasivas y puede alcanzar el $40 \%$.

Están descritos más de 90 serotipos bacterianos, $98 \%$ de los cuales cubre la vacuna PSV-23.

En la población general está indicada la vacunación de forma sistemática en adultos sanos mayores de 65 años, HIV positivos, pacientes con enfermedades crónicas (ICC, IR, cirrosis, EPOC, alcoholismo, dia- 
betes) y personas inmunocomprometidas con riesgo de enfermedad neumocócica o sus complicaciones (anesplenia funcional o anatómica, linfoma, mieloma, anemia falciforme, síndrome nefrótico, transplan$\operatorname{tados} . ..)^{2}$.

La vacuna es un polisacárido (PSV-23). Es una asociación de 23 polisacáridos capsulares correspondientes a los serotipos más prevalentes.

En pacientes con EII sin inmunocompromiso se aconseja dosis única. Se administrará una segunda dosis al cumplir los 65 años, pero sólo cuando hayan transcurrido más de 5 años desde la dosis previa.

En pacientes con EII con inmunocompromiso se debe administrar una segunda dosis de recuerdo si a los 5 años persiste la situación de inmunosupresión.

Datos publicados recientemente sugieren tasas de respuesta menores en pacientes con EII y tratamiento con fármacos biológicos, no así con otro tipo de IS, de ahí la importancia de indicar la vacunación cuanto antes ${ }^{19}$.

Se administra en dosis única (IM).

\section{Triple vírica (sarampión, rubéola, parotiditis)}

El sarampión se incluye dentro de las viriasis exantemáticas. El cuadro clínico agudo se caracteriza por fiebre, clínica óculo-nasal y respiratoria alta y exantema máculopapuloso. Las complicaciones aparecen con más frecuencia en niños pequeños en forma de otitis media, laringotraqueitis, neumonía o panencefalitis. En pacientes inmunosuprimidos pueden no estar presentes las lesiones cutáneas típicas y las tasas de mortalidad ser altas, sobre todo en relación a complicaciones respiratorias o neurológicas.

La rubeola es una enfermedad generalmente leve caracterizada por exantema cutáneo, adenopatías y febrícula. Cuando la primoinfección ocurre en una embarazada no inmune existe posibilidad de infección fetal con aparición de malformaciones congénitas (rubeola congénita).
La parotiditis es otra enfermedad vírica aguda en la que, además de las glándulas parótidas, puede haber compromiso del resto de glándulas salivares, SNC, páncreas, ovarios y testículos. Tiene baja mortalidad pero puede causar importantes secuelas en la fertilidad masculina.

Desde mediados de los años 80 está comercializada una vacuna combinada frente a los 3 virus (triple vírica), incluida en los calendarios vacunales de la población infantil.

En pacientes con EII, al igual que en población general, está indicada la vacunación universal ${ }^{2}$ Previamente deberemos conocer el estado de inmunidad frente a estos virus solicitando serología IgG específica frente a cada uno de ellos. Todas las personas con resultado negativo en alguna de las serologías deberían vacunarse.

El tipo de vacuna es con virus vivos atenuados.

En pacientes con EII sin inmunocompromiso seguiremos las pautas de población general; es decir, solicitar serología IgG y vacunar a los negativos.

En pacientes con EII y criterios de inmunocompromiso la vacuna está contraindicada. Por ello es de vital importancia determinar el estado de inmunidad en el momento del diagnóstico de la enfermedad. Sólo así podremos vacunar a los pacientes antes de iniciar un tratamiento IS. Incluso en el caso de que esto ya no sea posible se sigue aconsejando realizar serología IgG ya que, al igual que ocurre con la varicela, en este grupo de pacientes (inmunosuprimidos y no inmunizados) es muy importante asegurar una correcta inmunización del entorno más próximo para minimizar el riesgo de transmisión de la enfermedad.

Sólo en pacientes de elevado riesgo (personal sanitario y docente) podría estar justificada la retirada de la inmunosupresión durante 3 meses para vacunar al paciente, reintroduciéndolo al menos 2 semanas después.

Se administra en dos dosis separadas un mínimo de 20 días. Vía IM. 


\section{Varicela-zóster (VVZ)}

La primoinfección por el VVZ se caracteriza por un cuadro febril agudo asociado a erupción vesiculosa generalizada que se conoce como varicela. Tras la curación el virus permanece latente de forma indefinida, acantonado en los ganglios sensitivos. En determinadas circunstancias el virus puede reactivarse produciendo una infección localizada en la piel que se denomina herpes zóster.

En países occidentales más del $90 \%$ de las primoinfecciones ocurren antes de los 9 años. La incidencia global de complicaciones (neumonía, encefalitis...) es baja en niños sanos, aumentando en menores de 1 año, mayores de 15 años, inmunodeprimidos o pacientes con patología debilitante de base.

Se calcula que un tercio de los pacientes con varicela desarrollarán un herpes zóster a lo largo de su vida y de ellos el $10-18 \%$ presentarán una neuralgia postherpética. La neuralgia postherpética puede tener un curso recidivante y en ocasiones invalidante para el paciente.

En pacientes inmunodeprimidos este riesgo de presentación en forma de herpes zóster es mayor. Estudios realizados en pacientes con EII demuestran que la prevalencia es superior (mayor en EC que CU), sobre todo en aquellos en tratamiento con corticoides o fármacos tiopurínicos. Además, y a diferencia de otras complicaciones infecciosas, el zóster aparece fundamentalmente en pacientes que llevan más de un año de tratamiento.

La $\mathrm{ECCO}^{1}$, el ACIP (Advisory Committee on Inmunization Practices $)^{6}$ y la SEMPSPH $^{4}$ aconsejan la vacunación universal. En Navarra y el País Vasco está incluida en el calendario vacunal infantil. En adultos se aconseja en toda persona no inmunizada.

El tipo de vacuna es con virus vivos atenuados.

En pacientes con EII sin inmunocompromiso se aconsejará vacunación a todos los que tengan serología IgG negativa.

Al ser una vacuna elaborada a partir de virus vivos atenuados está contrain- dicada en sujetos inmunodeprimidos. En cualquier caso sigue siendo vital la inmunización del entorno más próximo de cara a evitar la transmisión de la enfermedad. Los convivientes con un paciente inmunosuprimido y no inmunizado pueden vacunarse sin necesidad de aislar al sujeto con EII. Aproximadamente el 5\% de los vacunados desarrollan un cuadro cutáneo leve similar al de la primoinfección; en estos casos sí se aconseja que el sujeto inmunosuprimido evite el contacto con ellos $^{20-21}$.

Se pauta en dos dosis separadas por 4-8 semanas. Administración SC.

En EE.UU. en 2006 se aprobó una vacuna frente al zóster, indicada en población general > 60 años sin evidencia de herpes zóster previo y que pretende evitar su aparición y/o reducir la severidad de su complicaciones $^{19}$. Al igual que la de la varicela es una vacuna viva atenuada.

\section{Papiloma virus (VPH)}

Se trata de la enfermedad de transmisión sexual más frecuente en el mundo. Además es causa de cáncer de cérvix. Existen más de 100 serotipos virales que se clasifican en función de su bajo o alto potencial oncológico. Los tipos 16 y 18 causan más de $70 \%$ de los casos de cáncer de cérvix.

Desde 2007 el MSC aconseja la vacunación universal. El momento ideal es previo al inicio de la actividad sexual, aconsejándose en mujeres entre 11-14 años. En EE.UU. el ACIP ${ }^{6}$ recomienda vacunación en todas las mujeres de entre 19-26 años, con independencia del estado de inmunización y la patología de base asociada.

La vacuna no sustituye la necesidad de seguimiento citológico ya que no se cubren todos los serotipos virales.

La infección carece de tratamiento específico pero, en caso de detectarla, permite intensificar los programas de prevención secundaria. Su diagnóstico no constituye una contraindicación para la inmunosupresión. En principio los IS no agravan el curso de la enfermedad, aun- 
que los tumores relacionados con VPH parecen ser más frecuentes en el grupo de mujeres inmunodeprimidas.

La vacuna es de tipo recombinante.

- Divalente (cubre serotipos 16-18): 3 dosis en los meses 0-1-6.

- Tetravalente (cubre serotipos 6-1116-18): 3 dosis en los meses 0-2-6.

En pacientes con EII y con independencia del estado de inmunización asumiremos las indicaciones de la población general, aconsejando a todas ellas revisiones periódicas por parte de ginecología y animando a la vacunación.

En pacientes con EII se describen alteraciones en la citología de cérvix con mayor prevalencia que en población general.

Se administra en tres dosis (IM). El intervalo dependerá del tipo de vacuna

\section{Meningococo $\mathrm{C}$}

\section{Neisseria meningitidis}

Es un coco gram positivo que puede colonizar la faringe de hasta el $10 \%$ de los humanos. Habitualmente desaparece tras semanas-meses. Puede producir un cuadro catarral de vías altas, en ocasiones seguido de una sepsis (meningococcemia) de curso fulminante, con o sin meningitis clínica asociada.

Están descritos 13 serogrupos con diferencias antigénicas en los polisacáridos capsulares.

Esta vacuna está incluida en el calendario vacunal infantil (2-4-15 meses).

La Sociedad Española de Medicina Preventiva aconseja vacunación sistemática en pacientes inmunosuprimidos.

La vacuna está constituida por oligosacáridos o polisacáridos:

- Monovalente (frente al serogrupo C): protección $97 \%$

- Divalente (frente a serogrupos A-C)

- Tetravalente (frente a serogrupos AC-W135-Y): protección del 85\% con descenso de títulos a los 3-5 años.

Como no existen pautas específicas para pacientes con EII asumiremos la indicación para el grupo de los inmunocom- prometidos, aconsejando vacunación en todos ellos.

La pauta es una dosis única (monovalente).

\section{Haemophilus influenzae tipo b (Hib)}

El género Haemophilus son cocobacilos gram negativos que forman parte de la flora comensal del tracto respiratorio superior. Por ello no es infrecuente que causen infecciones locales tipo laringitis, epiglotitis, otitis, gingivitis o abscesos dentarios. Se han descrito cuadros más severos en forma de neumonía y empiema y se estima que son responsables del 5\% de las endocarditis bacterianas.

La vacuna está incluida en el calendario vacunal infantil (2-4-6-18 meses).

En adultos las opiniones son discrepantes. En España la Sociedad de Medicina Preventiva ${ }^{4}$ aconseja su uso en todos los pacientes inmunosuprimidos. En EEUU ${ }^{6}$ la CDC (Center for Disease Control) limita su indicación a esplenectomizados, HIV positivos y pacientes con leucemia.

La vacuna es de tipo polisacárida. Administración IM

El polisacárido capsular se conjuga con toxoide tetánico en un intento por mejorar su inmunogenicidad, muy baja en $<18$ meses.

Está comercializada otra forma de vacuna conjugada con difteria, tétanos y tosferina. En este caso la parte de la tosferina es viva atenuada (componente celular de Bordetella pertusis) y por tanto no se debe administrar en pacientes inmunosuprimidos.

En EII, al igual que en el caso anterior y dada la ausencia de datos específicos para este grupo poblacional, asumiremos la indicación para el grupo de pacientes con criterios de inmunosupresión, indicando vacunación en todos ellos.

Se administra en dosis única

\section{PROPUESTA DE CIRCUITO PARA LA VACUNACIÓN EN EII}

Solicitar el calendario vacunal y realizar una analítica con las serologías pertinentes puede llevarse a cabo en nuestras propias 
consultas. A partir de este momento el circuito que pueden o deben llevar los pacientes variará en función de las características de cada centro. En aquellos centros en los que se haya alcanzado un consenso con el servicio de Medicina Preventiva los pacientes pueden ser derivados a sus consultas, de forma similar a lo que se realiza con pacientes inmunosuprimidos por cualquier otra circunstancia. Cuando esto no sea posible habremos de ser nosotros mismos los que indiquemos las vacunas concretas que requiere cada paciente, remitiéndolo entonces a su centro de salud para que se las administren. Aquellos hospitales que dispongan de una consulta específica de enfermería de EII pueden apoyarse en ella para que sean sus propias enfermeras las que vacunen a los pacientes.

Nosotros creemos que el abordaje multidisciplinar es la clave para el éxito en el tratamiento de los pacientes con EII. Ya no sólo necesitamos contar con el apoyo de cirujanos, dietistas, psicólogos o ATS con experiencia en el manejo de este tipo de patología, sino que dada la creciente complejidad de los tratamientos sería conveniente contar con un equipo de preventivistas de referencia que colaboren para alcanzar el éxito de los programas de vacunación.

Tabla 7. Tabla con información de vacunación según infección

\begin{tabular}{|c|c|c|}
\hline & EII sin inmunocompromiso & EII con inmunocompromiso \\
\hline DT & actualizar & actualizar \\
\hline Gripe & $>65$ años grupos de riesgo social & todos (anual) \\
\hline VHA & si VHA-IgG negativo & si VHA-IgG negativo \\
\hline VHB & todos $($ dosis $20 \mu \mathrm{g})$ & todos (dosis $40 \mu \mathrm{g})$ \\
\hline Neumococo & todos dosis única & todos repetir a los 5 años \\
\hline Triple vírica & si IgG negativa & contraindicada \\
\hline VVZ & si VVZ-IgG negativa & contraindicada \\
\hline VPH & † 11-14 años (<26 años) & q 11-14 años (<26 años) \\
\hline Meningo-C & - & dosis única \\
\hline $\mathrm{Hib}$ & - & dosis única \\
\hline
\end{tabular}

\section{BIBLIOGRAFÍA}

1. Rahier JF, Ben-Horin S, Chowers Y, Conlon C, De Munter P, D’Haens G, et al. European evidence-based Consensus on the prevention, diagnosis and management of opportunistic infections in inflammatory bowel disease. JCC 2009; 3: 47-91.

2. Ministerio de Sanidad y Consumo Español. Vacunación en adultos. Recomendaciones 2004. www.msc.es consultado en mayo de 2012.
3. Ministerio de Sanidad y Consumo Español. Vacunación en adultos. Recomendaciones de vacunación en difteria y tétanos. Actualización 2009.

4. Salleras L, Bayas JM, Calbo E, Campins M, Castrodeza J, Cerrillo A. Calendario de vacunación para los adultos que presentan determinadas condiciones médicas, exposiciones, conductas de riesgo o situaciones especiales. Sociedad Española de Medicina Preventiva, Salud Pública e Higiene. 2005. www. sempsph.com consultado en mayo de 2012 . 
5. Campins M, Martínez X, Cossío Y. Protocolo de vacunación de pacientes con enfermedad inflamatoria intestinal. 2012. SEMPSPH. En: www.sempsph.com (Consultado el 16 de abril de 2013).

6. Recommended Adult Inmunization Schedule. United States, 2011. MMWR 2011; 60: 1-4. www.cdc.gov/mmwr consultado en mayo de 2012.

7. Ricart E, García V, Barreiro M. Infecciones, vacunas y enfermedad inflamatoria intestinal, ¿qué necesitamos saber? Marge Médica Books, 2010. Ed.

8. Toruner M, Loftus E, Harmsen S, Zinsmeister A, Orenstein W, Sandborn J, Colombel JF, Egan L. Risk factors for opportunistic infections in patients with inflammatory bowel disease. Gastroenterology 2008; 138: 929-936.

9. García-Vidal C, Rodríguez-Fernández S, Teijón S, Esteve M, RodríGuez-Carballeira M, Lacasa JM et al. Risk factors for opportunistic infections in infliximab-treated patients: the importance of screening in prevention. Eur J Clin Microbiol Infect Dis 2009; 28: 331-337.

10. NELSON C. Vaccines and Inflammatory Bowel Disease. Dig Dis 2010; 28: 525-535.

11. Centers for Disease Control and Prevention. Hepatitis Surveillance Report $n^{\mathbf{a}} 59$. Atlanta 2004.

12. Gisbert JP, Chaparro M, Esteve M. Review article: prevention and management of hepatitis $\mathrm{B}$ and $\mathrm{C}$ infection in patients with inflammatory bowel disease. Aliment Pharmacol Ther 2011; 33: 619-633.

13. Loras C, Saro C, González-Huix F, Mínguez M, Merino $\mathrm{O}$ et al. Prevalence and factors related to hepatitis B and C and inflammatory bowel disease patients in Spain: a nationwide, multicenter study. Am J Gastroenterol 2009; 104: 57-63.
14. Vida Pérez L, Gómez Camacho F, García Sánchez V, Iglesias Flores EM, Castillo Molina L, Cerezo Ruiz A et al. Eficacia de la vacuna contra el virus de la hepatitis B en pacientes con enfermedad inflamatoria intestinal. Med Clin (Barc) 2009; 132: 331-335.

15. Chaparro M, Villagrasa JR, Rodríguez-Nogueiras A, GISBERT JP. Inmune response to hepatitis B vaccination in patiente with inflammatory bowel disease. Gastroenterology 2010; 138: S197.

16. Gisbert JP, Menchén L, García-Sánchez V, Marín I, Villagrasa JR, Chaparro M et al. Comparison of the effectiveness of two protocols for vaccination (standard and double dosage) against hepatitis $B$ virus in patients with inflammatory bowel disease. Aliment Pharmacol Ther 2012; 35: 1379-1385.

17. WHO publication. Hepatitis B vaccunas: WHO position paper-recommendations. Vaccine 2009; 28: 589-590.

18. Moisés J, Alkhouri N, Shannon A, Raig K, López R, DANZIGER-ISAKOV L et al. Hepatitis B immunity and response to booster vaccination in children with inflammatory bowel disease treated with infliximab. Am J Gastroenterol 2012; 107: 133-138.

19. Fiorino G, Peyrin-Biroulet L, Naccarato P, Szabo $\mathrm{H}$, Sociale O, Vetrano $\mathrm{S}$, et al. Effects of inmunosuppresion on inmune response to Pneumococcal vaccine in inflammatory bowel disease: a prospective study. Inflamm Bowel Dis 2012; 18: 1042-1047.

20. Wasan SK, Baker SE, Skolnik PR, Farraye F. A practical guide to vaccinating of inflammatory bowel disease patient. Am J Gastroenterol 2010; 105: 1231-1238.

21. Marin M, Güris D, Chaves SS, Schmid S, Seward JF. Prevention of varicella recommendations of the Advisory Committee in Inmunization Practices (ACIP). MMWR 2007; 56: 1-40. 